\title{
Assessment of relevant factors with respect to psychosocial properties in potential living donor candidates before liver transplantation
}

This article was published in the following Dove Press journal:

Neuropsychiatric Disease and Treatment

Ming-Kung Wu,' Li-Wen Hsu, ${ }^{2}$ Kuang-Tzu Huang, ${ }^{3}$ Chih-Che Lin, ${ }^{2}$ Chih-Chi Wang, ${ }^{2}$ Ting-Lung Lin, ${ }^{2}$ Wei-Feng Li, ${ }^{2}$ Shigeru Goto, ${ }^{2}$ Chao-Long Chen, ${ }^{2}$ Chien-Chih Chen'

'Department of Psychiatry, Kaohsiung Chang Gung Memorial Hospital and Chang Gung University College of Medicine, Kaohsiung, Taiwan; ${ }^{2}$ Liver Transplantation Center and Department of Surgery, Kaohsiung Chang Gung Memorial Hospital and Chang Gung University College of Medicine, Kaohsiung, Taiwan; ${ }^{3}$ Institute for Translational Research in Biomedicine, Kaohsiung Chang Gung Memorial Hospital and Chang Gung University College of Medicine, Kaohsiung, Taiwan

Correspondence: Chao-Long Chen Liver Transplantation Center and Department of Surgery, Kaohsiung Chang Gung Memorial Hospital and Chang Gung University College of Medicine, I 23 Ta-Pei Road, Niao-Sung Dist., Kaohsiung 83305, Taiwan

Tel +88677317123 ext 3302

Fax +88677324855

Email clchen@cgmh.org.tw

Chien-Chih Chen

Department of Psychiatry, Kaohsiung Chang Gung Memorial Hospital and Chang Gung University College of Medicine, 123 Ta-Pei Road, Niao Sung District, Kaohsiung 83305, Taiwan

Tel +886773 I 7I23 ext 8753

Fax +88677326817

Email chenfather@adm.cgmh.org.tw
Background: Living donor liver transplantation (LDLT) has been developed as one of gold standard treatments for end-stage liver disease. Mental health is a required selection criterion for adult living liver donors and may influence the quality of life after operation.

Patients and methods: A total of 1,210 potential living donor candidates for liver transplantation (LT) underwent psychosocial evaluation that included a semi-structured interview, multi-choice self-reported inventory (Beck Depression Inventory-2nd edition [BDI-II], Beck Anxiety Inventory [BAI]), and the family APGAR (Adaptability, Partnership, Growth, Affection, Resolve) index. The test results were compared by family relationships, and subgroups were classified based on the donation type: 1) parents to children, 2) grown children to parents, 3) siblings to siblings, 4) spouses to spouses, and 5) other relatives to other relatives.

Results: The BDI-II $(P<0.001)$ and BAI differed considerably according to the donation type in potential donor candidates. Compared with other subgroups, parents donating to their children suffered the most severe psychological stress before LDLT and exhibited more depressive $(P<0.001)$ and anxiety symptoms. However, the stress associated with grown children donating to their parents, siblings, and spouses was not significantly higher than it was for other relatives. Furthermore, a significant negative correlation existed between family APGAR scores and the severity of depression and anxiety $(P<0.001)$ among potential donor candidates.

Conclusion: These results indicate the importance of understanding potential donor candidates' psychological characteristics before LT. Greater anxiety and depression may be exhibited by parent donors due to the distress from fears of death or illness of the recipients, or their guilty feeling for their child. Additionally, family dysfunction also revealed more depression and anxiety. Such donor candidates should be given more extensive pre-donation counseling for minimizing pre-LDLT psychological stress.

Keywords: living donor candidates, psychosocial evaluation, depression, anxiety, family function, family relationship

\section{Introduction}

Liver transplantation (LT) provides a solution for patients affected by end-stage cirrhosis, fulminant disease, and inborn error of metabolism problems. Living donor liver transplantation (LDLT) is a widely accepted therapy for end-stage liver disease owing to the severe shortage of cadaveric donor liver grafts. LDLT has recently increased substantially in Europe ${ }^{1}$ and Asia. ${ }^{2}$ Some investigations have found a considerable increase in overall recipient survival in LDLT compared with deceased donor LT when analyzed based on an intention-to-treat approach. ${ }^{3,4}$ However, living donor partial hepatectomy offers donors no physical benefit, and the rate of mortality 
immediately following liver harvesting is $0.2 \%-1.0 \% .^{5-7}$ Additionally, donors exhibited increased depression before surgery, and mental quality of life decreased following LDLT. ${ }^{8}$ Depressive symptoms have consistently been shown to be associated with an increased risk of long-term mortality in recipients after LT. ${ }^{9,10}$ Hence, preoperative psychological assessments are considered effective for predicting postoperative mental responses and psychological problems. However, the preoperative psychological status of the donor has not been systematically investigated. Therefore, protecting donors from psychosomatic harm is a key consideration in donor evaluation. ${ }^{11}$ The purpose of the psychological evaluation prior to living organ donation is to ascertain whether the donor has carefully considered the donation, is free of coercion or significant ambivalence, and understands the donation process. The evaluation also includes a survey to identify potential donor candidates who are emotionally vulnerable or who suffer from psychiatric disorders. Problematic donation types that could induce psychosocial and psychiatric complications following transplantation are also detected during the evaluation process.

The close personal relationships between recipients and donors provide reasons to anticipate high psychosocial pressure, as well as feelings of ambivalence, anxiety, and fear among donors prior to the operation. ${ }^{8,12}$ Accordingly, the influence of preoperative feelings depends strongly on the donor's decision-making process, including the donor's motivation for donating, the manner of donor decision making, the donor selection process among family members, and the extent to which the donor attributes positive characteristics to the recipient. Other factors, such as individual donor characteristics, urgency of transplantation, donorrecipient emotional closeness, and other stressors, may also exert mediating effects on the decision-making process and contribute decisively to the long-term donor's emotional stability. ${ }^{8,12-14}$ Unfortunately, a few studies have examined LDLT donors in Asia, ${ }^{15-17}$ also, a few studies have explored the influence of donation types on the psychological stress of living liver donors.

The coverage provided by the Taiwan National Health Insurance has enabled the establishment of rigid and clear protocol-based guidelines for donor selection criteria. Accordingly, Taiwan Human Organ Transplantation Act stipulates that donor candidates who are first-degree to fifth-degree relatives of the recipients or have close relationships with the recipients may be considered. Since performing the first successful cadaveric LT in Asia, ${ }^{18}$ by the end of 2016, 1,384 of the $1,595(86.8 \%)$ liver transplants performed at Kaohsiung
Chang Gung Memorial Hospital (CGMH) in Taiwan were LDLT. This single-center study aimed to explore the psychosocial characteristics of adult living donor candidates before LT. This study also examined the influence of donation types on the psychological stress of potential living liver donor candidates, using a multi-choice self-report inventory (Beck Depression Inventory-2nd edition [BDI-II] and the Beck Anxiety Inventory [BAI]). We also explored the correlation between psychological stress and family function of potential donor candidates using family APGAR (Adaptability, Partnership, Growth, Affection, Resolve) test scores.

\section{Patients and methods Study design}

This is a retrospective study in which we analyzed the chart data of surgical evaluation from all potential donor candidates, who are first-degree to fifth-degree relatives of the recipients or have close relationships with the recipients at the Liver Transplant Center of Kaohsiung CGMH before LDLT. Ethics approval was obtained from the Institutional Research Ethics Committee of CGMH, Taiwan (Approval No CGMH 104-1219B), and the committee also waived the need for patient consent. The data were collected as part of the routine psychosomatic clinical care and adequate provisions were in place to protect the confidentiality of the data. Between 2011 and 2016, 1,210 potential donor candidates for adult or pediatric LDLT fulfilled the enrollment criteria, which included adequate language skills and permanent residency in Taiwan. The potential donor candidates were assessed with respect to their psychological stress by assessing for symptoms of anxiety and depression using the Chinese versions of the BDI-II and BAI. Family function was measured using the Chinese version of the family APGAR index. The test results were compared among the subgroups classified according to the donation type: 1) parents to their children, 2) grown children to their parents, 3) adult siblings to adult siblings, 4) spousal donations, whether husband to wife or wife to husband, and 5) donations to other relatives, defined as relatives other than the abovementioned relations or collateral relatives.

\section{Questionnaires and analysis strategy BDI-II}

The BDI-II is an internationally and widely used screening instrument for assessing depression severity. ${ }^{19}$ The test possesses good psychometric properties, and has high reliability and internal consistency. ${ }^{20,21}$ The BDI-II is a self-report questionnaire that comprises 21 items, and individual answers are assessed on a four-point scale, with 
scores ranging from 0 to 3 . The degree of depression is scored as follows: $0-13=$ normal to minimal depression; 14-19= mild depression; $20-28=$ moderate depression; and 29-63 = severe depression. Current suicidal ideation was assessed by responses to item nine of the inventory $(0=$ no thoughts of killing myself; 1 = thoughts of killing myself; $2=$ would like to kill myself; 3 = would kill myself if I had the chance). The potential donor candidates were required to rate each item on the scale, selecting the value that best represented their mood. Higher scores predict more severe depressive symptoms.

\section{BAl}

Anxiety studies primarily focus on organ transplant recipients. However, donors' quality of life and their psychological conditions, such as anxiety and depression, have been receiving more attention in organ transplant nowadays. ${ }^{14,22-25}$ We aimed to determine the anxiety levels of potential donor candidates via the BAI questionnaire. The BAI assesses the severity of patient anxiety. ${ }^{26}$ The 21 -item self-report questionnaire possesses good psychometric properties and has high reliability and internal consistency. ${ }^{27}$ The BAI comprises both physiological and cognitive components of anxiety addressed through descriptions of subjective, somatic, or panic-related symptoms in various aspects of the individual's life. The simplified Chinese version of the BAI has similar psychometric properties. ${ }^{28}$ The answers are rated on a four-point Likert scale ranging from 0 to 3 (where $0=$ never, $1=$ sometimes, 2 = frequently, 3 =always). The degree of anxiety is scored as follows: $0-9=$ normal to minimal anxiety; $10-18=$ mild anxiety; 19-29 = moderate anxiety. The established cutoff point of $\geq 30$ corresponds to severe anxiety disorder. The potential donor candidates were required to rate each item on the scale such that it best represented their current affect.

\section{Family APGAR index}

Psychosocial or family function was measured using the family APGAR index. ${ }^{29,30}$ The family APGAR index is a five-item self-report questionnaire that measures perceived family function in the domains of adaptation, partnership, growth, affection, and resolve. The scale is scored by summing the values for the five items to obtain a total score that can range from 0 to 10 and can be categorized as "good" (scores from 7 to 10), "moderate dysfunction" (score from 4 to 6), or "severe dysfunction" (score from 0 to 3 ). In this study, higher scores indicated greater satisfaction with family function (scores from 7 to 10$),{ }^{29}$ while lower scores, ie, below 6 , denoted family dysfunction. ${ }^{31}$

\section{Statistical analysis}

Data were analyzed using Statistical Package for Social Sciences software version 17.0 (SPSS, Inc., Chicago, IL, USA). For descriptive analyses, the data were expressed as means and standard deviations. The mean differences in continuous variables were compared using Pearson correlation and variance, followed by the Scheffe test, according to the score level and parameter distribution. The following variables were tested as impact factors of psychological stress in potential donor candidates: demographics (sex, age, donating type, marital status, educational level, occupation, living with recipient) and decision making during donation process (own initiative and consultation that led to the inclination). Given the exploratory nature of this study, variables that were related to the BDI-II, BAI, and family APGAR index at $P<0.10$ in the univariate analyses were included in the multivariate analyses. Multiple linear regressions with backward elimination were used to test independent factors of potential donor candidates' psychological stress and family function (using $P<0.05$ for retention in the model).

\section{Results}

\section{Potential donor candidates' demographic characteristics}

Table 1 provides a detailed description of the potential donor candidates' demographics and donation-specific characteristics. The total sample consisted of 1,210 participants $(49.2 \%$ male and $50.8 \%$ female) with a mean age of $31.8 \pm 8.56$ years (range 18-59 years). Regarding marital status of the potential donor candidates, 687 (56.8\%) were single, 473 (39.1\%) were married, and $50(4.1 \%)$ were separated or divorced at the time of the study. The relationships between the potential donor candidates and the recipients were categorized into subgroups based on the donation type: parents to their children, $6.6 \%$; grown children to their parents, $66.1 \%$; siblings, $8.4 \%$; spouses, $5.9 \%$; and other relatives, $13.0 \%$.

\section{Analysis of influences impacting mental health and family function \\ Multivariate analyses}

Variables that were related to the affective composite score and family function in the univariate analyses at $P<0.10$ were evaluated using multiple linear regression to determine whether each predictor made a unique contribution to the result (Table 2). Donation type was found to be a significant contributor to depression severity and anxiety of the potential donor candidates, whereas educational levels were found to be significant relative to family function. 
Table I Potential donor candidates' demographic characteristics

\begin{tabular}{|c|c|}
\hline Variable & Total $(n=1,2 \mid 0)(n[\%])$ \\
\hline \multicolumn{2}{|l|}{ Sex } \\
\hline Male & $595(49.2)$ \\
\hline Female & $615(50.8)$ \\
\hline Age (years) (range) & $31.8 \pm 8.56(18-59)$ \\
\hline Parents & $36.7 \pm 7.28(23-54)$ \\
\hline Children & $29.2 \pm 6.73(18-54)$ \\
\hline Siblings & $40.4 \pm 8.6 \mid(\mid 8-55)$ \\
\hline Spouses & $43.4 \pm 6.75(3 \mathrm{I}-58)$ \\
\hline Other relatives & $31.8 \pm 9.15(18-59)$ \\
\hline \multicolumn{2}{|l|}{ Donation type } \\
\hline Parents & $80(6.6)$ \\
\hline Children & $800(66.1)$ \\
\hline Siblings & $102(8.4)$ \\
\hline Spouses & 7I (5.9) \\
\hline Other relatives & $157(13.0)$ \\
\hline \multicolumn{2}{|l|}{ Marital status } \\
\hline Single & $687(56.8)$ \\
\hline Married & $473(39.1)$ \\
\hline Separate/divorced & $50(4.1)$ \\
\hline \multicolumn{2}{|l|}{ Educational level } \\
\hline Primary/Junior school & $92(7.6)$ \\
\hline Senior high school & $384(3 \mid .7)$ \\
\hline College & $636(52.6)$ \\
\hline Masters and $\mathrm{PhD}$ & $98(8.1)$ \\
\hline \multicolumn{2}{|l|}{ Occupation } \\
\hline Housewife & $107(8.8)$ \\
\hline Employed & $872(72.1)$ \\
\hline Student & $145(12.0)$ \\
\hline Unemployed & $86(7.1)$ \\
\hline \multicolumn{2}{|l|}{ Live with recipient } \\
\hline Yes & $569(47.0)$ \\
\hline No & $562(46.4)$ \\
\hline Excluded (missing data) & $79(6.5)$ \\
\hline
\end{tabular}

Note: Data are presented as mean \pm SD unless otherwise specified.

\section{Donation type variances in mental health}

According to the study data, significant differences were found between the groups with respect to depression $(F=13.576, P<0.001)$. As shown in Table 3, parents donating to their children exhibited the highest scores for depression, followed by siblings and spouses. Comparing the degree of depression by the donation type, significant differences were observed between donor parents and donor grown children $(P<0.001)$, between donor parents and donor siblings $(P=0.001)$ as well as donor spouses $(P=0.003)$, and between donor parents and other donor relatives $(P<0.001)$. Concerning anxiety $(F=3.917, P=0.004)$, significant differences were found between parents donating to their children and grown children donating to their parents $(P=0.012)$ and between parents donating to other relatives $(P=0.010)$.

\section{Correlations between mental health and family function}

The correlations between depression, anxiety, and family function were evaluated (Table 4). As expected, the APGAR
Table 2 Comparisons between potential donor candidates' mental health, APGAR, and donor characteristics: multiple linear regression

\begin{tabular}{|c|c|c|c|}
\hline & \multicolumn{3}{|c|}{ Multiple linear regression } \\
\hline & b & $95 \% \mathrm{Cl}$ & $P$-value \\
\hline \multicolumn{4}{|l|}{ BDI-II } \\
\hline Sex & 1.120 & $(0.434, I .805)$ & 0.001 \\
\hline Age & 0.019 & $(-0.030,0.069)$ & 0.443 \\
\hline \multicolumn{4}{|l|}{ Donation type ${ }^{a}$} \\
\hline Parents & 6.279 & $(4.59 I, 7.966)$ & $<0.001$ \\
\hline Children & 2.286 & $(1.224,3.348)$ & $<0.001$ \\
\hline Siblings & 2.043 & $(0.56 \mathrm{I}, 3.526)$ & 0.007 \\
\hline Spouses & 2.324 & $(0.524,4.124)$ & 0.011 \\
\hline \multicolumn{4}{|l|}{ Educational level ${ }^{\mathrm{b}}$} \\
\hline Primary/Junior school & $0.47 I$ & $(-1.230,2.172)$ & 0.587 \\
\hline Senior high school & 1.419 & $(0.121,2.716)$ & 0.032 \\
\hline College & 0.523 & $(-0.705,1.75 \mathrm{I})$ & 0.403 \\
\hline \multicolumn{4}{|l|}{ Occupation $^{c}$} \\
\hline Housewife & 0.422 & $(-1.309,2.152)$ & 0.633 \\
\hline Employed & -0.925 & $(-2.22 I, 0.372)$ & 0.162 \\
\hline Student & 0.400 & $(-1.976,1.177)$ & 0.619 \\
\hline \multicolumn{4}{|l|}{ BAI } \\
\hline Sex & 1.502 & $(0.915,2.088)$ & $<0.001$ \\
\hline Age & 0.055 & $(0.013,0.098)$ & 0.017 \\
\hline \multicolumn{4}{|l|}{ Donation type ${ }^{a}$} \\
\hline Parents & 2.564 & $(1.122,4.007)$ & 0.001 \\
\hline Children & 1.166 & $(0.258,2.074)$ & 0.012 \\
\hline Siblings & -0.026 & $(-1.293,1.242)$ & 0.969 \\
\hline Spouses & 0.287 & $(-1.27||, 806)$, & 0.733 \\
\hline \multicolumn{4}{|l|}{ Educational level } \\
\hline Primary/Junior school & 1.347 & $(-0.107,2.80 I)$ & 0.069 \\
\hline Senior high school & $\mathrm{I} .359$ & $(0.249,2.468)$ & 0.016 \\
\hline College & 0.699 & $(-0.35 \mathrm{I}, \mathrm{I} .748)$ & 0.192 \\
\hline \multicolumn{4}{|l|}{ Occupation } \\
\hline Housewife & 0.303 & $(-1.176,1.783)$ & 0.688 \\
\hline Employed & -0.755 & $(-1.864,0.353)$ & 0.182 \\
\hline Student & 0.018 & $(-1.330,1.366)$ & 0.979 \\
\hline \multicolumn{4}{|l|}{ Family APGAR } \\
\hline \multicolumn{4}{|l|}{ Marital status ${ }^{d}$} \\
\hline Single & -0.297 & $(-1.021,0.425)$ & 0.420 \\
\hline Married & $0.58 \mathrm{I}$ & $(0.58 \mathrm{I}, 0.372)$ & 0.118 \\
\hline \multicolumn{4}{|l|}{ Educational level } \\
\hline Primary/Junior school & -1.039 & $(-1.745,-0.334)$ & 0.004 \\
\hline Senior high school & -0.878 & $(-1.422,-0.334)$ & 0.002 \\
\hline College & -0.188 & $(-0.707,0.33 \mathrm{I})$ & 0.477 \\
\hline
\end{tabular}

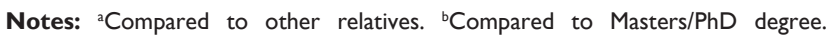
'Compared to unemployed. ${ }^{\mathrm{d}}$ Compared to separate/divorced.

Abbreviations: APGAR, adaptability, partnership, growth, affection, resolve; BDI-II, Beck Depression Inventory-2nd edition; BAI, Beck Anxiety Inventory.

scores were negatively correlated with both the BDI-II and BAI scores, while the BDI-II scores were positively correlated with the BAI scores. The correlation coefficients between the APGAR scores and the BDI-II and BAI scores were -0.326 and -0.241 , respectively. Meanwhile, the correlation coefficient between the BDI-II and BAI was 0.611. The data listed in Table 5 imply that poor family satisfaction or family dysfunction (APGAR score $\leq 6$ ) ${ }^{31}$ was strongly related 
Table 3 Comparison of degree of depression and anxiety on donation type (post hoc Scheffe test)

\begin{tabular}{llll}
\hline & $\begin{array}{l}\text { Donation } \\
\text { type }\end{array}$ & $\begin{array}{l}\text { Mean } \\
\text { difference }\end{array}$ & P-value \\
\hline BDI-II & & & \\
Parents vs & Children & 4.586 & $<0.00$ I \\
& Siblings & 3.916 & 0.001 \\
& Spouses & 3.947 & 0.003 \\
& Other relative & 5.829 & $<0.001$ \\
BAI & & & \\
Parents vs & Children & 2.094 & 0.012 \\
& Siblings & 2.068 & 0.102 \\
& Spouses & 1.408 & 0.556 \\
& Other relative & 2.486 & 0.010 \\
\hline
\end{tabular}

Abbreviations: BDI, Beck Depression Inventory; BAI, Beck Anxiety Inventory.

to depression $(\mathrm{b}=3.832,95 \% \mathrm{CI} 3.056,4.608, P<0.001)$ and anxiety $(\mathrm{b}=2.374,95 \%$ CI $1.732,3.016, P<0.001)$ compared to family satisfaction.

\section{Discussion}

LDLT helps provide the maximum benefits for end-stage liver disease patients by reducing wait time mortality. The goals of LDLT are not only to minimize donor risk and ensure safe donor surgery but also to assess the living donors' psychological traits and provide the donors with the appropriate preoperative psychological support. Accordingly, several investigators have recently explored the psychological stress on living adult donors prior to donation, ${ }^{14,32-35}$ and have reported that living donors require extensive counseling before donation. Specifically, our study pointed out that relationship is a major factor that affects potential donor candidates' psychological stress.

In our study, we assessed the mental health of a large sample of potential living donor candidates. A significant difference was found between education level and psychological stress. DuBay et al reported that donors with higher education exhibited significantly worse mental health. ${ }^{35}$ However, less psychological stress was found in the present study group, in which potential donor candidates with advanced education

Table 4 Pearson correlations for both mental health and family APGAR score $(n=1,210)$

\begin{tabular}{lllll}
\hline Variable & & BDI-II & BAI & APGAR \\
\hline BDI-II & Pearson correlation & I & - & - \\
& Sig. (2-tailed) & & & \\
BAI & Pearson correlation & $0.61 \mathrm{I}$ & $\mathrm{I}$ & - \\
& Sig. (2-tailed) & $<0.00 \mathrm{I}$ & & \\
APGAR & Pearson correlation & -0.326 & $-0.24 \mathrm{I}$ & $\mathrm{I}$ \\
& Sig. (2-tailed) & $<0.00 \mathrm{I}$ & $<0.00 \mathrm{I}$ & \\
\hline
\end{tabular}

Abbreviations: APGAR, adaptability, partnership, growth, affection, resolve; BDI-II, Beck Depression Inventory-2nd edition; BAI, Beck Anxiety Inventory.
Table $\mathbf{5}$ The effect of family function on mental health

\begin{tabular}{|c|c|c|c|c|}
\hline & \multirow[t]{3}{*}{$\begin{array}{l}\text { Satisfaction }(n=922) \\
\text { Family APGAR } \\
\text { score }>6\end{array}$} & \multicolumn{3}{|c|}{$\begin{array}{l}\text { Dysfunction }(n=288) \\
\text { Family APGAR } \\
\text { score } \leq 6\end{array}$} \\
\hline & & \multicolumn{3}{|c|}{ Multiple linear regression } \\
\hline & & b & $95 \% \mathrm{Cl}$ & $P$-value \\
\hline BDI-II & - & 3.832 & $(3.056,4.608)$ & $<0.001$ \\
\hline BAI & - & 2.374 & $(1.732,3.016)$ & $<0.001$ \\
\hline
\end{tabular}

showed lower levels of depression and anxiety. One possible reason for this discrepancy is that potential donor candidates with higher levels of education could search for detailed information about the process in websites, books, and print media; the obtained information could improve their mental health status. Another possibility is that the Ministry of Health and Welfare in Taiwan regularly publishes the organ transplantation outcomes to ensure public awareness and transparency. Our hospital is the highest volume center in Taiwan (Kaohsiung CGMH) and has the highest 3-year survival rate at $91 \%$. The 1- and 5-year survival rates for pediatric LDLT for biliary atresia at this center (98\% each) are among the highest in the world. ${ }^{36,37}$ According to our results, we will provide more information such as survival rate, low bleeding, and donor mortality in LDLT to the potential donor candidates with lower levels of education to reduce their psychological stress in future cases.

As expected, family function was correlated with depression and anxiety in potential donor candidates. The results of this study showed that potential donor candidates from families exhibiting high family satisfaction experienced lower levels of depression and anxiety compared to potential donor candidates from families exhibiting dysfunction. Family members from highly functioning families may feel more responsible to serve as organ donors; both donors and recipients from these types of families have stronger family emotional support. By contrast, low family satisfaction was highly correlated with lower levels of happiness and greater degrees of individual stress..$^{38}$

This study also drew comparisons among subgroups based on the donation type. Parents donating to their children differed markedly with respect to depression and anxiety from other subgroups. The increased psychological stress of parents differed from that of children, siblings, spouses, and other relatives. Parent donors may exhibit greater anxiety and depression due to distress based on their fears of death or illness of the recipient, or due to their guilty feeling for their child. Many children admitted in our hospital had biliary atresia and accepted LT at an age of 1 year or less. 
The study data indicate that donor parents usually experience no ambivalence and are naturally highly motivated in their decision making (98.8\%). This investigation also suggests that the parent-child relationship is inherent, and parents involved in LT are more concerned about their children than themselves.

When comparing grown children donors and other donation types (except for parents to their children), children donating to parents did not exhibit higher levels of depression and anxiety than the other subgroups. On the other hand, other relatives exhibited the lowest symptoms of depression and anxiety compared to other subgroups of living donors in the present study. This phenomenon may be explained by the lower emotional proximity between donors and recipients; one can assume that the lower psychological stress and the lack of a moral obligation permit freedom of choice and less emotional distress. Noma et al found lower mental distress among spousal donors, as these donors have their own families and are possibly seeking to avoid inter familial conflicts in the donor selection process. ${ }^{39}$ However, the degrees of depression and anxiety among spouses were lower only than those of the parents donating to children subgroup. Among spousal donation, 90.1\% of the LDLT recipients were males, and the underlying disease requiring treatment with LT was chronic liver failure in patients in the prime of life, ie, between 35 and 53 years and an average of 46 years of age. Regarding the demographics of the potential donor candidates, the mean age was 43.4 years, the range was between 31 and 58 years, and $64.8 \%$ were employed. Therefore, the high affective scores among the spousal donors may reflect a lack of disability income before transplantation, and these donors may continue to suffer ailments that further limit their return to work following surgery.

Our observational findings suggest a need for psychosocial evaluation of potential donor candidates before LT. However, it is more difficult to design such preoperative evaluation program, due to current limited medical resources. Our results provide a quick selection for clinicians to take notices of donor's psychological stress according to the donation type and family function.

There are limitations in this study. First, our study did not compare primary diagnosis to the donation type, which may affect our results. Second, we did not determine whether the donors were all independent or whether multiple donors may be linked to a given transplant candidate. As we lacked prospective information regarding the donor candidates from their first consideration through the actual decision as well as data on the precise role of psychosocial factors in their final decision and their concerns about donation, it is evident that there are other areas of the donation decision-making process that were not assessed. Finally, this study was a cross-sectional study. We did not follow-up for any probable adverse effects of the donors or potential donor candidates after LDLT. Therefore, our further study should focus on long-term evaluation of the donors' quality of life such as Short Form-36 (SF-36) questionnaire and its correlations of primary diagnosis of the recipients and the donation type.

\section{Conclusion}

In living donor organ donation, one crucial precondition is the health of the donor. However, potential donor candidates represent a healthy sample who are subjected to emotional and mental stress, whether they serve as actual living donors or not. Our results show that psychological stress in potential donor candidates is affected by the donation type. It is remarkable that parents donating to their children suffered the most severe psychological stress before LDLT. Additionally, family dysfunction was strongly positively correlated with depression and anxiety of potential donor candidates. This may require more extensive psychological support prior to LDLT donation and post-donation psychosocial follow-up.

\section{Acknowledgments}

This work was supported in part by grants from the Ministry of Science and Technology (MOST 105-2314-B-182A-058 and MOST 106-2314-B-182A-086 to CC-C; MOST 105-2314B-182A-037-MY2 to CL-C), and CGMH (CMRPG8D1013 to CL-C) of Taiwan. We appreciate the Biostatistics Center, Kaohsiung CGMH for statistics work.

\section{Disclosure}

The authors report no conflicts of interest in this work.

\section{References}

1. Nadalin S, Capobianco I, Panaro F, et al. Living donor liver transplantation in Europe. Hepatobiliary Surg Nutr. 2016;5(2):159-175.

2. Chen CL, Kabiling CS, Concejero AM. Why does living donor liver transplantation flourish in Asia? Nat Rev Gastroenterol Hepatol. 2013; 10(12):746-751.

3. Shah SA, Levy GA, Greig PD, et al. Reduced mortality with right-lobe living donor compared to deceased-donor liver transplantation when analyzed from the time of listing. Am J Transplant. 2007;7(4):998-1002.

4. Berg CL, Gillespie BW, Merion RM, et al; A2ALL Study Group. Improvement in survival associated with adult-to-adult living donor liver transplantation. Gastroenterology. 2007;133(6):1806-1813.

5. Middleton PF, Duffield M, Lynch SV, et al. Living donor liver transplantation - adult donor outcomes: a systematic review. Liver Transpl. 2006;12(1):24-30.

6. Mulligan D. Living donor liver transplantation and donor graft size: how small can we go to reduce risk to the donor and what is the cost to the recipient? Liver Transpl. 2009;15(11):1392-1394. 
7. Ishizaki M, Kaibori M, Matsui K, Kwon AH. Change in donor quality of life after living donor liver transplantation surgery: a single-institution experience. Transplant Proc. 2012;44(2):344-346.

8. Walter M, Bronner E, Steinmüller T, Klapp BF, Danzer G. Psychosocial data of potential living donors before living donor liver transplantation. Clin Transplant. 2002;16(1):55-59.

9. Corruble E, Barry C, Varescon I, Falissard B, Castaing D, Samuel D. Depressive symptoms predict long-term mortality after liver transplantation. J Psychosom Res. 2011;71(1):32-37.

10. Russell RT, Feurer ID, Wisawatapnimit P, Salomon RM, Pinson CW. The effects of physical quality of life, time, and gender on change in symptoms of anxiety and depression after liver transplantation. $J$ Gastrointest Surg. 2008;12(1):138-144.

11. Erim Y, Beckmann M, Valentin-Gamazo C, et al. Selection of donors for adult living-donor liver donation: results of the assessment of the first 205 donor candidates. Psychosomatics. 2008;49(2):143-151.

12. Walter M, Bronner E, Pascher A, et al. Psychosocial outcome of living donors after living donor liver transplantation: a pilot study. Clin Transplant. 2002;16(5):339-344.

13. Switzer GE, Dew MA, Simmons RG. Donor ambivalence and postdonation outcomes: implications for living donation. Transplant Proc. 1997 29(1-2): 1476 .

14. Erim Y, Beckmann M, Kroencke S, et al. Influence of kinship on donors' mental burden in living donor liver transplantation. Liver Transpl. 2012; 18(8):901-906.

15. Toyoki Y, Ishido K, Kudo D, et al. Donor quality of life after living donor liver transplantation: single-institute experience. Transplant Proc. 2012;44(2):341-343.

16. Togashi J, Sugawara Y, Tamura S, et al. Donor quality of life after living donor liver transplantation: a prospective study. J Hepatobiliary Pancreat Sci. 2011;18(2):263-267.

17. Hayashi A, Noma S, Uehara M, et al. Relevant factors to psychological status of donors before living-related liver transplantation. Transplantation. 2007;84(10):1255-1261.

18. Chen CL, Wang KL, Lee MC, et al. Liver transplantation for Wilson's disease: Report of the first successful liver transplant in Taiwan. Jpn J Transplant. 1987;22:178-184.

19. Beck AT, Steer RA, Brown GK. Manual for the Beck Depression Inventory-II. San Antonio, TX: Psychological Corporation; 1996.

20. Jay CL, Butt Z, Ladner DP, Skaro AI, Abecassis MM. A review of quality of life instruments used in liver transplantation. J Hepatol. 2009; 51(5):949-959.

21. Lu ML, Che HH, Chang SW, Shen WW. [Reliability and validity of the Chinese version of the Beck Depression Inventory-II]. Taiwan J Psychiatry. 2002;16(4):301-309. Chinese [with English abstract].

22. Pérez-San-Gregorio MÁ, Martín-Rodríguez A, Luque-Budia A, Conrad R. Concerns, mental health, and quality of life in living kidney donation-parent donor candidates worry less about themselves. Front Psychol. 2017;11(8):564.

23. Pérez-San-Gregorio MÁ, Fernández-Jiménez E, Luque-Budia A, Martín-Rodríguez A. Anxiety and concerns in Spanish living kidney donor candidates. Int J Psychiatry Med. 2015;50(2):163-177.
24. Gökçe S, Durmaz O, Peykerlı Gürsu G, et al. Assessment of living donors with respect to pre- and posttransplant psychosocial properties and posttransplant family functioning in pediatric liver transplantation. Turk J Gastroenterol. 2011;22(1):36-41.

25. Frade IC, Fonseca I, Dias L, et al. Impact assessment in living kidney donation: psychosocial aspects in the donor. Transplant Proc. 2008; 40(3):677-681.

26. Beck AT, Epstein N, Brown G, Steer RA. An inventory for measuring clinical anxiety: psychometric properties. J Consult Clin Psychol. 1988; 56(6):893-897.

27. Che HH, Lu ML, Chen HC, Chang SW, Lee YJ. [Validation of the Chinese version of the Beck Anxiety Inventory]. Formos J Med. 2006;10(4):447-454. Chinese [with English abstract].

28. Cheng SK, Wong CW, Wong KC, et al. A study of psychometric properties, normative scores and factor structure of Beck Anxiety Inventorythe Chinese version. Chin J Clin Psychol. 2002;10(1):4-6.

29. Smilkstein G. The family APGAR: a proposal for a family function test and its use by physicians. J Fam Pract. 1978;6(6):1231-1239.

30. Smilkstein G, Ashworth C, Montano D. Validity and reliability of the Family APGAR as a test of family function. J Fam Pract. 1982;15(2): 303-311.

31. Mengel M. The use of the family APGAR in screening for family dysfunction in a family practice center. J Fam Pract. 1987;24(4):394-398.

32. Schulz KH, Kroencke S, Beckmann M, et al. Mental and physical quality of life in actual living liver donors versus potential living liver donors: a prospective, controlled, multicenter study. Liver Transpl. 2009;15(12): $1676-1687$.

33. Narumi S, Umehara M, Toyoki Y, et al. Importance of awareness of perioperative social and physical situations of living donors for liver transplantation. Transplant Proc. 2012;44(2):328-331.

34. Togashi J, Sugawara Y, Akamatsu N, et al. Quality of life after adult living donor liver transplantation: a longitudinal prospective follow-up study. Hepatol Res. 2013;43(10):1052-1063.

35. DuBay DA, Holtzman S, Adcock L, et al. Adult right-lobe living liver donors: quality of life, attitudes and predictors of donor outcomes. Am J Transplant. 2009;9(5):1169-1178.

36. Chen CL, Concejero A, Wang CC, et al. Living donor liver transplantation for biliary atresia: a single-center experience with first 100 cases. Am J Transplant. 2006;6(11):2672-2679.

37. Concejero A, Chen CL, Wang CC, et al. Living donor liver transplantation for hepatocellular carcinoma: a single-center experience in Taiwan. Transplantation. 2008;85(3):398-406.

38. Chao J, Zyzanski S, Flocke S. Choosing a family level indicator of family function. Fam Syst Health. 1998;16(4):367-374.

39. Noma S, Hayashi A, Uehara M, Uemoto S, Murai T. Comparison between psychosocial long-term outcomes of recipients and donors after adult-to-adult living donor liver transplantation. Clin Transplant. 2011;25(5):714-720.
Neuropsychiatric Disease and Treatment

\section{Publish your work in this journal}

Neuropsychiatric Disease and Treatment is an international, peerreviewed journal of clinical therapeutics and pharmacology focusing on concise rapid reporting of clinical or pre-clinical studies on a range of neuropsychiatric and neurological disorders. This journa is indexed on PubMed Central, the 'PsycINFO' database and CAS,

\section{Dovepress}

and is the official journal of The International Neuropsychiatric Association (INA). The manuscript management system is completely online and includes a very quick and fair peer-review system, which is all easy to use. Visit http://www.dovepress.com/testimonials.php to read real quotes from published authors. 